\section{Optimal support}

Streamline your professional workflow with the high performance OPMI Pico microscope supplied by Nuview. This cutting-edge system is ergonomically designed to provide optimal support during complex procedures - including restorative dentistry, endodontics, implantology and periodontics.

Featuring a wide range of magnification settings, the OPMI Pico microscope is available with either an integrated LED or xenon light source for improved visibility and clarity. It also offers the benefits of Varioskop 100, which enables users to conveniently adjust the focal length without leaving their preferred working position, thus preventing the risk of strain and fatigue.

For more information please call Nuview on 01453 872266, email info@nuview-ltd. com, visit http://www.voroscopes.co.uk or 'like' Nuview on Facebook.

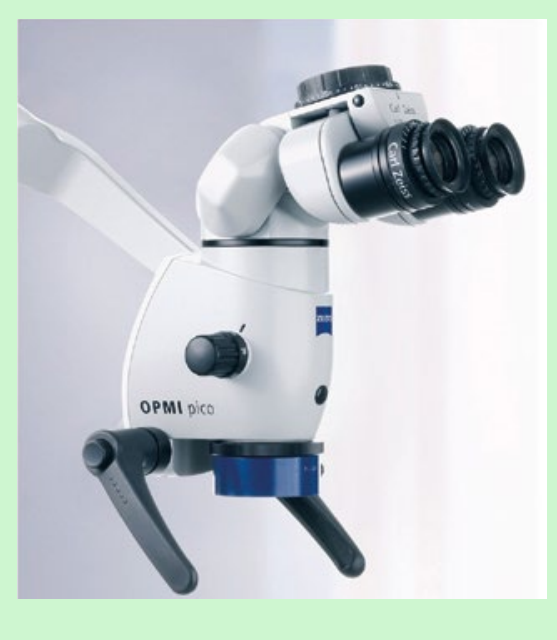

\title{
Keep your patients smiling with confidence
}

Solvay Dental 360 has custom-developed Ultaire AKP as a modern, metal-free alternative to traditional removable partial dentures (RPDs).

Specifically designed to fit the digital workflow, this new generation material offers an accurate fit with superior retention and aesthetics. Ultaire AKP is lightweight yet it does not distort and is remarkably strong and resilient. It also has a bone-like feel and is highly compliant, which makes it pleasant and comfortable to wear.

Biocompatible with absolutely no metallic taste, partial dentures made from this long-life

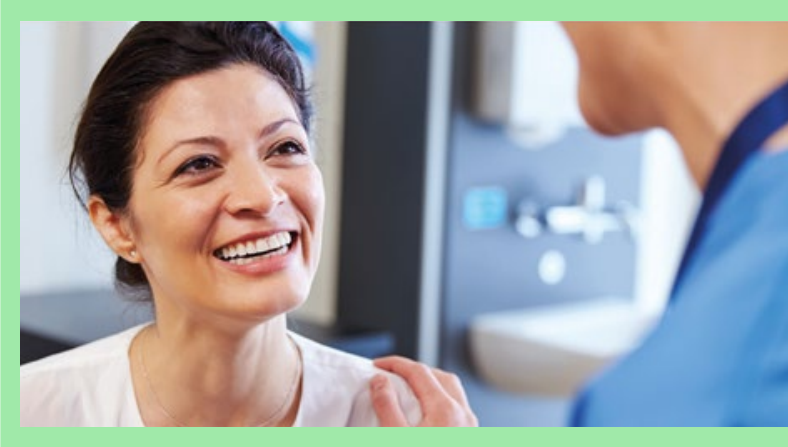
polymer will keep your patients smiling with confidence for years to come.

To book a Solvay Dental 360 Professional Lunch and Learn or to find out more information about Ultaire AKP and Dentivera milling discs visit www. solvaydental360.com.

\section{Quality implant care}

Many patients choose to travel abroad for affordable dental implants, leaving themselves vulnerable to poor quality treatment. Remind patients of the value in professional care within the UK by referring them to the awardwinning Ten Dental Facial team.

Led by experienced implant surgeons Drs Nik Sisodia and Martin Wanendeya, the

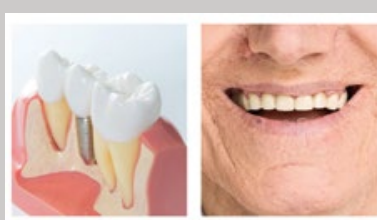

team is well equipped with the knowledge and skills required to perform implant treatment safely and successfully. You can also feel confident knowing that the team will keep you informed throughout treatment so that you remain integral to the referral process.

Save patients from the risks of cheap implant treatment by contacting Ten Dental Facial on 0203393 2623, office@tendental.com or by visiting www.tendental. com.

\section{Digital excellence series announced}

Align Technology, Inc. (NASDAQ: ALGN) have announced that throughout October 2019 it will be hosting the Digital Excellence Series - Powered by iTero, a new event series for dental professionals in the United Kingdom.

The events will be hosted in Birmingham, Motherwell, Manchester and London, with a focus on the benefits of the iTero intraoral scanner and dental professionals' most frequently asked questions regarding how to transform their practice from a traditional, analogue model, towards a digital one.

Key topics will include: $\rightarrow$ Why embrace digital technology - what are the benefits for my practice?

$\rightarrow$ The advantages of digital workflows versus analogue workflows

$\rightarrow$ Understand the full capabilities of iTero, and how an iTero digital scanner brings value across the entire digital workflow

$\rightarrow$ The benefits and impact of a digital workflow on the patient journey

$\rightarrow$ The benefits of the latest iTero innovation, iTero Element 5D with NIRI technology.

The dates and locations for the Digital

Excellence Series of meetings are as follows: $\rightarrow 12$ October in Birmingham (09:30 - 12:30) at the Align Technology UK Office

$\rightarrow$ 16 October in Motherwell, Scotland (18:30 - 21:00) at the Dakota Hotel Eurocentral

$\rightarrow 23$ October in Manchester (18:30 - 21:00) at the Victoria Warehouse

$\rightarrow 30$ October in London $(18: 30-21: 00)$ at Rocket Space

The events are complimentary to attend; however, registration is required. Please contact your local Invisalign or iTero representative, or Stevie Broomfield: sbroomfield@aligntech.com 07500993440. 